\title{
"humanidades
}

Revista Humanidades

ISSN: 2215-3934

humanidades@ucr.ac.cr

Universidad de Costa Rica

Costa Rica

\section{La violencia sin huella. Un estudio sobre los estereotipos femeninos y de la violencia como obstáculos en la judicialización de denuncias en Querétaro, México}

Córdova Esparza, Mtra. Karen Edith; Terven Salinas, Dra. Adriana

La violencia sin huella. Un estudio sobre los estereotipos femeninos y de la violencia como obstáculos en la judicialización de denuncias en Querétaro, México

Revista Humanidades, vol. 12, núm. 1, e48592, 2022

Universidad de Costa Rica, Costa Rica

Disponible en: https://www.redalyc.org/articulo.oa?id=498068490004

\section{(c) (1) @ $\Theta$}

Esta obra está bajo una Licencia Creative Commons Atribución-NoComercial-SinDerivar 3.0 Internacional. 
Desde los estudios étnicos, culturales, de género y ambientales

\title{
La violencia sin huella. Un estudio sobre los estereotipos femeninos y de la violencia como obstáculos en la judicialización de denuncias en Querétaro, México
}

\author{
Violence Without a Trace. A Study about Female Stereotypes and Violence as Obstacles in the Prosecution of \\ Complaints in Queretaro, Mexico
}

Mtra. Karen Edith Córdova Esparza

Universidad Autónoma de Querétaro, Querétaro, México

Redalyc: https://www.redalyc.org/articulo.oa?

kcordova16@alumnos.uaq.mx

iD https://orcid.org/0000-0003-1130-8871

Dra. Adriana Terven Salinas

Universidad Autónoma de Querétaro, Querétaro, México

adriana.terven@uaq.mx

iD https://orcid.org/0000-0001-7236-9614

$\mathrm{id}=498068490004$

Recepción: 01 Agosto 2021

Aprobación: 10 Septiembre 2021

\begin{abstract}
RESUMEN:
El presente artículo muestra, desde una perspectiva crítica feminista del derecho, algunos de los obstáculos para la judicialización de casos de violencia moral contra mujeres en la justicia penal en la ciudad de Querétaro, México. El estudio se realizó con base en etnografía en espacios de justicia y etnografía feminista, mediante observación de procesos de denuncia de mujeres-víctimas en el Centro de Justicia para Mujeres en Querétaro, entrevistas semiestructuras a operadoras de justicia y entrevistas a profundidad a mujeres víctimas de violencia, elaboradas, respectivamente, durante los periodos de febrero-abril y septiembre-octubre de 2020 . A partir de lo anterior se encontró que los estereotipos acerca del deber ser de las mujeres y el estereotipo de que la violencia ejercida contra las mujeres adopta, predominantemente, la forma de violencia física, se constituyen en obstáculos para el procesamiento en la esfera penal de la violencia moral, cuyo carácter es sutil y se manifiesta sin dejar huellas físicas. Por consiguiente, desde una perspectiva crítica feminista, que observa al derecho no como una unidad objetiva y neutral, sino como productor de género, se plantea que estos estereotipos prolongan las relaciones asimétricas de poder entre mujeres y hombres dentro del orden patriarcal.

Palabras ClaVe: moral, violencia, derecho penal.
\end{abstract}

\section{Abstract:}

The paper shows, from a critical feminist perspective of law, some of the obstacles to the prosecution of cases of moral violence against women in the criminal justice system of Queretaro. The study was carried out based on ethnography in spaces of justice and feminist ethnography, by observing the complaint processes of women-victims in the Center for Justice for Women in Querétaro, semi-structural interviews with justice operators and, in-depth interviews with women victims of violence, prepared, respectively, during the periods February-April and September-October 2020. It was found that stereotypes about the duty of women and the stereotype that violence against women, predominantly takes the form of physical violence, constitute obstacles to the prosecution in the criminal sphere of moral violence, which character is subtle and manifests itself without leaving physical traces. Consequently, it is proposed that from a critical feminist perspective that observes the law not as an objective and neutral unit but as a producer of gender, it is possible to find that these stereotypes continue to maintain asymmetric power relations between women and men in the patriarchal order.

KEYWORDS: moral, violence, criminal law.

\section{INTRODUCCIÓN}

A partir de los años setenta diversas organizaciones no gubernamentales (principalmente feministas) y organismos internacionales plantearon la necesidad de procurar el respeto hacia los derechos de las mujeres, 
así como la obligación del Estado de protegerlos y garantizarlos, lo cual ha generado la instauración de marcos jurídicos a nivel internacional, nacional y local. A pesar de la vigencia de estos ordenamientos en México desde finales del siglo XX y la implementación del modelo de justicia penal acusatorio en 2008, que busca proteger el respeto hacia los derechos de las víctimas, las mujeres continúan enfrentando diversos obstáculos en el acceso a la justicia penal.

En este artículo se analiza la manifestación de los estereotipos sobre el deber ser de las mujeres. Dichos estereotipos son sustentados por una moral patriarcal. Asimismo, se configuran como parte inherente de la interpretación y la aplicación de las normas durante la atención de denuncias. Esto produce la exclusión de formas de violencia no visibles. En el sistema penal la violencia moral no es tomada en consideración sino que es introducida como un complemento de delitos o de la violencia física, ya que la mayoría de los casos, cuando son judicializados, se clasifican como lesiones (Lachenal, 2016). Lo anterior permitió observar cómo el estereotipo de la violencia que deja huella, aunado a los estereotipos de género, se configuran en obstáculos para la judicialización de la violencia moral en el ámbito de la justicia penal en la ciudad de Querétaro, México.

Ahora bien, la metodología utilizada para la realización de la investigación fue el trabajo de campo etnográfico, colocando en el centro de la reflexión a las mujeres para rescatar sus voces. Es decir, se retoma la etnografía feminista, la cual de acuerdo con Castañeda (2012) problematiza:

(...) la posición de las mujeres, al dejar de considerarlas, solo como informantes, para considerarlas creadoras culturales, y al mismo tiempo, identificar, analizar e interpretar, las orientaciones, contenidos y sesgos de género que las colocan a ellas, a los varones y otras categorías sociales genéricas en posiciones diferenciadas (p. 221).

Asimismo, se recurrió a la etnografía en espacios de justicia para documentar el proceso de denuncia y judicialización de la violencia moral en Querétaro y así "percibir valores e ideologías diferentes de aquello que informan explícitamente los discursos oficiales” (Kant y Lupetti, 2014, p. 3). Desde esta estrategia metodológica, ${ }^{1}$ se observó cómo en dicho proceso se conjuntan estereotipos acerca del deber ser de las mujeres víctimas de violencia, los cuales están implícitos en la ley, así como en las prácticas de las personas operadoras de justicia. De igual manera, se detectaron estereotipos acerca de lo que significa la violencia, entendida como aquella fuerza ejercida sobre alguien que siempre deja huellas observables.

De esta manera, se realizó trabajo de campo en el Centro de Justicia para Mujeres en Querétaro, donde se ubica la Unidad IV de la Fiscalía General del Estado. También se llevaron a cabo entrevistas semiestructuradas a operadoras de justicia y a mujeres víctimas de violencia, en particular, a aquellas cuyas denuncias fueron desestimadas.

El artículo se estructura de la siguiente manera: inicialmente, se expone en términos generales el marco jurídico internacional y nacional de combate a la violencia contra las mujeres, en contraste con los retos que las mujeres continúan enfrentando cuando acuden a la justicia penal a interponer una denuncia. Además, se retoma la perspectiva crítica feminista que concibe al derecho como creador de género (Núñez, 2018) dicha perspectiva permite dar luz a los estereotipos de las personas operadoras de justicia respecto a cómo debe ser una mujer víctima y cómo estos estereotipos inciden en la construcción de los hechos jurídicos cuando se trata de casos de violencia moral.

En el siguiente apartado, se abordan los conceptos de patriarcado, violencia moral y moral patriarcal para destacar el carácter estructural de la violencia ejercida contra las mujeres como producto del orden patriarcal que las coloca en oposición y subordinación a los hombres (Segato, 2003). Una de las expresiones de esta violencia es la violencia moral, la cual reposa en una moral tradicional, es decir, el orden moral que se establece en el patriarcado es masculino (Hierro, 1990). De esta manera, los valores asociados a lo femenino inciden en la interpretación de las denuncias que son realizadas por las mujeres y en la clasificación de los conflictos.

Enseguida, a través de tres ejemplos etnográficos, se muestra qué ocurre cuando la violencia es denunciada. Se advierte cómo las denuncias son desestimadas de manera preliminar por las personas operadoras de justicia y cómo los estereotipos normalizan y descontextualizan la violencia comprendida desde la estructura 
patriarcal. Esto trae como consecuencias la invisibilización y la simplificación de violencias que no dejan huellas o marcas físicas, como es el caso de la violencia moral, la cual puede ocurrir a través de gestos, miradas o actos que no implican una crueldad de orden físico (Segato, 2003).

Finalmente, en las conclusiones se plantea que en el proceso de denuncia de violencia que realizan las mujeres el derecho penal y su aplicación no es neutral en términos de género. Lo anterior se constituye como un obstáculo para la judicialización de la violencia moral, pero también como un mecanismo que produce y reproduce un tipo de género que no contraviene a la hegemonía masculina conservando el orden patriarcal existente.

\section{EL DERECHO COMO PRODUCTOR DE GÉNERO Y LA DENUNCIA PENAL. UNA PERSPECTIVA DE ANÁLISIS}

La violencia contra las mujeres por razones de género es un tema que desde la década de 1970 escaló al ámbito internacional, lo que trajo consigo un cambio significativo en la forma de concebirse, al dejar de considerarla como un problema exclusivamente del ámbito de lo privado por lo que trascendió al escenario de lo público. En este proceso han estado involucradas diversas organizaciones no gubernamentales, principalmente feministas, y organismos como la Organización de las Naciones Unidas (ONU), desde donde se han generado recomendaciones a los Estados para que protejan y garanticen los derechos de las mujeres.

Desde entonces, continúan multiplicándose la suma de eventos como convenciones y conferencias, ${ }^{2}$ las intervenciones de otros organismos internacionales como la Organización Mundial de la Salud y el Banco Mundial, ${ }^{3}$ las promulgaciones y ratificaciones por parte de los estados nacionales ${ }^{4}$ que coinciden en el entendido de que la violencia contra las mujeres constituye una violación de los derechos humanos. Como resultado, se han realizado cambios en materia legislativa y de políticas públicas en México, por ejemplo, la tipificación de la violencia familiar como un delito en 1997, la creación del Instituto Nacional de las Mujeres en 2001 y la promulgación de la Ley General de Acceso a las Mujeres a una vida Libre de Violencia en 2007.

La creación de ordenamientos legales en México permitió crear un marco jurídico nacional en materia del combate de la violencia contra las mujeres. Posteriormente, en el contexto de instauración del sistema de justicia penal acusatorio en 2008, ${ }^{5}$ se siguen realizando acciones, por ejemplo, en 2013 se creó el protocolo para juzgar con perspectiva de género de la Suprema Corte de Justicia de la Nación. En este mismo año se publicó la Ley General de Víctimas. En el año 2014 se expidió el Código Nacional de Procedimientos Penales y en 2019 se creó la Fiscalía Especial para los Delitos de Violencia Contra las Mujeres y Trata de Personas.

Sin hacer la reseña completa de todas las acciones realizadas, el corpus institucional es bastante robusto, sin embargo, las mujeres que viven violencia continúan enfrentando diversos obstáculos en el acceso a la justicia penal. La figura desde la cual se observan estas problemáticas es desde la víctima. Si bien estos ordenamientos legales promueven la protección de las víctimas y obligan a prestar ayuda, protección y reparación integral del daño (Fromow, 2018), la realidad demuestra situaciones adversas para estas.

El análisis que se propone retoma los estereotipos acerca del deber ser de las mujeres-víctimas. Nazira Álvarez (2016) plantea que mediante los estereotipos femeninos "se sanciona y se autorregula la conducta femenina transgresora de los valores establecidos por la colectividad" (p. 2), desde los cuales las mujeres son valoradas en atención al deber ser/hacer asignado para cada género. En este artículo se muestra la manera como estos estereotipos se configuran en obstáculos para la judicialización de la violencia, en particular, cuando se trata de violencia moral.

$\mathrm{Al}$ respecto, Casas (2010) plantea esta problemática al referirse al tratamiento que reciben las mujeres cuando son víctimas de delitos sexuales, la víctima ideal debe tener "huellas concretas de violencia física que puedan dar cuenta que la relación sexual no fue consentida” (p. 124). Cuando no es así, muchas de las denuncias son desestimadas de manera preliminar por las fiscalías (desistimiento de la acción penal) y muchas 
investigaciones no proceden porque no se considera el relato de la víctima como prueba. La autora también habla de la aplicación de peritajes e interrogatorios destinados a probar la honestidad de la víctima.

Estos desencuentros de las mujeres víctimas de violencia con el sistema de justicia penal, de acuerdo con Casas (2010), se manifiestan desde "la definición de ciertos tipos penales en que los prejuicios de género son parte inherentes de las normas tanto por la aplicación de la protección de las mujeres cuando estas son víctimas de delitos" (p. 119). En este sentido, la creación, interpretación y aplicación de las normas están mediadas por roles y estereotipos de género (Facio, 1992; Spaventa, 2002; Núñez, 2015).

A su vez, cuando se tipifica la violencia se hace desde un sentido diferente al del combate de la violencia contra las mujeres, tipificación reseñada en la larga trayectoria expuesta en los párrafos iniciales y tal como se muestra en el apartado 3.1. del presente artículo a través de casos empíricos. Al respecto Lachenal (2016) señala:

(...) el derecho penal no define ni sanciona como tal la violencia contra las mujeres, a excepción de la violencia intrafamiliar, sino las conductas antijurídicas que van a configurar un delito penal como lo son las lesiones y los homicidios/feminicidios, que atentan a la integridad física de las mujeres (p. 14).

Lo anterior también provoca la exclusión de otras formas de violencia no visibles, como es la violencia moral, la cual, en todo caso, es introducida como un complemento de delitos o de la violencia física. No obstante, la violencia contra las mujeres no se extingue en el homicidio/feminicidio o en aquellos actos que dejan huellas físicas o sexuales. Desde una perspectiva feminista, "la coacción moral, la sospecha, la intimidación, la condenación de la sexualidad, la desvalorización cotidiana de la mujer como persona, de su personalidad y sus trazos psicológicos, de su cuerpo, de sus capacidades intelectuales" (Segato, 2003, p. 115) son conductas que también deben ser consideradas como violencia.

Para llevar a cabo la discusión sobre la problematización expuesta hasta aquí se retoma la perspectiva crítica feminista del derecho ${ }^{6}$ que, a su vez, lo concibe (al derecho) como productor de género. El análisis se complementa con el debate en torno a la relación entre patriarcado y violencia moral, para desembocar en la experiencia empírica a partir del registro de casos de mujeres que buscaron interponer una denuncia en la Unidad IV de la Fiscalía General del Estado, ubicada en el Centro de Justicia para Mujeres en Querétaro (CEJUM).

La crítica feminista al derecho en general plantea que existen diferentes etapas en el desarrollo de la idea con respecto a que el derecho crea género. De acuerdo con la tipología de Carol Smart, presentada por Lucía Núñez (2018), en la primera etapa se plantea que el derecho es sexista. En la segunda etapa se postula que el derecho es masculino. Finalmente, en la tercera etapa, se propone que el derecho crea género, lo cual no implica abandonar por completo las propuestas anteriores, sino que se trata de una visión más avanzada en torno al análisis del derecho, debido a que:

(...) no intenta analizar la aplicación del derecho a sujetos ya predeterminados en cuanto al género sino que analiza al derecho como productor de identidades. En tal sentido el objeto de estudio se desplaza hacia las formas y sistemas jurídicos que crean y perpetúan las significaciones de la diferenciación de género (Núñez, 2018, p. 20).

En esta postura, basada en los planteamientos de Carol Smart, se señala que el derecho funciona concibiendo a las y los sujetos con relación a un atributo principal: el género. De esta manera, el derecho es un discurso que no solamente produce las diferencias de género, sino también formas específicas de dichas diferencias. Por esta razón, la autora nos invita a cuestionarnos “ ¿cómo funciona el género dentro del derecho y cómo funciona el derecho para crear género?” (Núñez, 2018, p. 20). De acuerdo con Lucía Núñez (2018), este nivel de análisis permite conocer, desde una perspectiva feminista, cuál es el tipo de mujer que se ha construido desde el derecho.

Esta perspectiva admite dar luz a los estereotipos de género sustentados en la moral patriarcal, los cuales son producidos y reproducidos en el discurso de la ley y su aplicación (práctica) por las personas operadoras de justicia cuando se denuncian y judicializan casos de violencia contra mujeres. En específico, revela cómo 
las concepciones de las mujeres-víctimas, en tanto sujetas dotadas de género (en oposición y subordinación a los varones), influyen en la construcción de los hechos jurídicos cuando se trata de casos que envuelven violencia moral.

En relación con el sistema penal en particular, ámbito en el que se desarrolla la investigación, de acuerdo con Haydée Birgin (2000), coexisten posturas feministas que solicitan la extensión del ámbito de intervención del poder punitivo. Uno de sus argumentos se centra en señalar que "las agencias penales no dan el tratamiento correspondiente a los conflictos que tienen como víctimas a las mujeres porque los subestiman debido a la discriminación de género inherente al derecho androcéntrico que nos rige” (p. 14). Es decir, desde estas perspectivas se plantea que el derecho puede ser utilizado y, en particular, el sistema de justicia penal, como mecanismo para contrarrestar la violencia ejercida contra las mujeres. A estas posturas se les conoce como el feminismo punitivo.

Otras posturas establecen que quienes argumentan a favor del uso del sistema jurídico penal no consideran que:

(...) el derecho penal no tiene la función de proveer a la víctima de las soluciones que busca. El diseño de los sistemas penales no prevé canales de realización de los derechos de las víctimas. Su blanco es el comportamiento "desviado" (Birgin, 2000, p. 14).

Siendo así, el sistema penal no solamente puede discriminar por cuestiones de género a las mujeres víctimas de violencia, sino que este actúa cuando los delitos (conductas desviadas) ya se han cometido.

De esta manera, autoras como Haydée Birgin (2000), Lucila Larrandart (2000), Graciela Otano (2000), Tamar Pitch (2018), entre otras, postulan que utilizar el derecho, en general, y el sistema penal, en particular, para combatir la violencia contra las mujeres no solo constituye una ilusión, sino que, además, es peligroso, porque este se encuentra fundado en lógicas masculinas y patriarcales. En cuanto al sistema penal, este es concebido como un instrumento de control social discriminatorio por excelencia y recurrir a su intervención significaría, paradójicamente, utilizar métodos discriminatorios para combatir la discriminación (Birgin, 2000).

Por su parte, Núñez (2018) establece que, si bien no se puede prescindir del derecho y del sistema penal, estos deben ser utilizados con cautela, sobre todo, cuando se trata de un problema complejo como lo es la violencia contra las mujeres, en tal sentido, propone el acercamiento al abolicionismo de su uso en una versión moderada, esto es: el minimalismo penal. Mediante esta propuesta la autora busca "tomar en cuenta la responsabilidad y participación del Poder (así, con mayúscula) en la reificación de una ideología de género opresiva y desigual" (Núñez, 2018, p. 14). Es decir, desde esta perspectiva, lo que se pretende es desentrañar las subjetividades en torno al género -en específico hacia las mujeres- que se ubican por detrás de la aplicación e interpretación de la ley en el contexto latinoamericano.

La propuesta de Núñez (2018) convoca a revelar las maneras en cómo el derecho crea género, a partir de estereotipos que oprimen y excluyen a las mujeres en el ámbito de la justicia. De allí que en el presente artículo se exponga el momento de la denuncia, ya que un gran número de estas son desestimadas. El análisis sobre las experiencias de mujeres que acudieron al Centro de Justicia para Mujeres en Querétaro permitió observar el papel que juegan los estereotipos de género, en particular, sobre la mujer-victima en el desistimiento de la acción penal.

\section{ORDEN PATRIARCAL Y LA VIOLENCIA MORAL}

En América Latina, la violencia contra las mujeres ha sido caracterizada como un fenómeno multifactorial debido a que se manifiesta de múltiples formas, sus causas no están determinadas y sus consecuencias sociales no son lineales ni siempre previsibles (Segato, 2003). La violencia se vincula con la pobreza, la dominación de lo masculino sobre lo femenino y la construcción latinoamericana del macho como estructura social que 
produce y reproduce injusticia social (Lachenal, 2016). Este contexto es posible observarlo a partir de la teoría de la opresión entre los géneros, en la cual tanto la diferencia como la desigualdad entre mujeres y hombres obedecen a una forma de organización social denominada patriarcado, ${ }^{7}$ desde esta estructura social es posible ubicar a la violencia ejercida contra las mujeres como parte de la dinámica tradicional de las relaciones de poder y dominación establecidas entre los géneros en el sistema patriarcal.

En esta perspectiva se inscriben los planteamientos de Rita Segato sobre patriarcado y violencia moral. Para Segato (2003), el patriarcado se constituye como una estructura de relaciones que se reviste de género, fija y reproduce, mediante posiciones jerárquicas marcadas por diferencias de poder y prestigio, a hombres y a mujeres. Los géneros surgen como posiciones asimétricas, por esta razón, el patriarcado se constituye como la simiente de las relaciones de poder en la sociedad, lo cual significa que, para Segato (2003), no existe poder sin subordinación, "ambos son subproductos de un mismo proceso, una misma estructura, posibilitada por la usurpación de un ser por el otro” (p. 31).

La autora advierte que estas relaciones asimétricas entre los géneros no son exactamente observables debido a que se trata de una estructura de relaciones con un carácter eminentemente abstracto, el cual se reviste de múltiples significados que pueden ser perceptibles, pero no se reduce a dichos significados porque "el poder se revela a veces, con infinita sutileza" (Segato, 2003, p. 56). El patriarcado puede ser expresado en un nivel simbólico "como la estructura inconsciente que conduce los afectos y distribuye valores entre los personajes del escenario social” (Segato, 2003, p. 14); de igual manera es expresado en un nivel de discursos y representaciones, lo cual implica pensar en la ideología de género dominante en una sociedad y en un determinado nivel de prácticas.

Para Segato (2003), el patriarcado, como estructura de poder que sustenta las relaciones desiguales entre mujeres y hombres, produce la violencia ejercida contra las mujeres cuando estas incumplen con los estereotipos de género asignados e internalizados como la manera de ser propia de las mujeres. Específicamente, la autora señala: "la violencia resulta del mandato moral y moralizador de reducir y aprisionar a la mujer en su posición subordinada, por todos los medios posibles, recurriendo a la violencia sexual, psicológica o física, manteniendo una violencia estructural" (p. 107). Una de las manifestaciones de esa violencia es la violencia moral, la cual se constituye como "el más eficiente de los mecanismos de control social y reproducción de las desigualdades” (p. 114), lo anterior sucede porque este tipo de violencia logra presentarse sin agresiones físicas o sin agresión verbal, manifestándose mediante gestos, actitudes o miradas.

Históricamente, la figura jurídica de la violencia moral se había definido de manera restringida. En el siglo $\mathrm{XX}$, bajo las nuevas concepciones de la violencia impulsadas por los derechos humanos y los feminismos, la coacción moral y psicológica, la violencia moral comienza a entenderse, en sentido amplio, como la perdida de la autonomía de las víctimas, esto es:

(...) la vulnerabilidad a la violencia moral y al maltrato psicológico por parte de los subordinados en un sistema de estatus las mujeres y los niños- pasó a ser asociada con el menoscabo del ejercicio independiente de la voluntad y con la libertad de elección (Segato, 2003, p. 109).

En la actualidad, la violencia moral, psicológica o emocional se encuentra plasmada en diferentes instrumentos jurídicos nacionales e internacionales, por ejemplo, en la Ley General de Acceso a las Mujeres a una Vida Libre de Violencia, en el Artículo n. ${ }^{\circ}$ 6, fracción I, se establece que la violencia psicológica es:

(...) cualquier acto u omisión que dañe la estabilidad psicológica, que puede consistir en: negligencia, abandono, descuido reiterado, celotipia, insultos, humillaciones, devaluación, marginación, indiferencia, infidelidad, comparaciones destructivas, rechazo, restricción a la autodeterminación y amenazas, las cuales conllevan a la víctima a la depresión, al aislamiento, a la devaluación de su autoestima e incluso al suicidio (Ley General de Acceso a las Mujeres a una Vida Libre de Violencia, 2007, p. 3).

A pesar de su definición como tipo específico de violencia en el ámbito de la justicia penal, por lo general, es introducida como complemento de la violencia física o es asociada a los primeros momentos en la escala de la 
violencia. En ese sentido, Segato (2003) plantea separar de manera analítica la violencia moral de la violencia física, puesto que su característica más importante no se refiere al hecho de que a través de ella se continúa o se amplía la violencia física, sino al hecho de que su carácter es difuso, sutil y omnipresente. La eficacia de la violencia moral reside en la aceptación social de comportamientos que son considerados como naturales o costumbres, en su arraigo en valores morales, familiares y religiosos y en la incapacidad para nombrarla o percibir sus consecuencias.

Siendo así, la violencia moral es una forma eficaz de subordinación y opresión de las mujeres y Segato (2003) la define como todo aquello que:

(...) envuelve agresión emocional, aunque no sea ni consiente ni deliberada, entran aquí: la ridiculización, la coacción moral, la sospecha, la intimidación, la condenación de la sexualidad, la desvalorización cotidiana de la mujer como persona, de su personalidad y sus trazos psicológicos, de su cuerpo, de sus capacidades intelectuales, de su trabajo y de su valor moral (p. 115).

Esta definición de Segato (2003) se plantea desde un sentido diferente al establecido en la ley, la autora prefiere llamarla violencia moral y no psicológica. De esta manera, la perspectiva se mueve de lugar porque deja de ser concebida como un problema psicológico de la mujer-víctima, para sustentar la violencia moral en una moral tradicional que reposa en una violencia rutinaria. "Afirmo así que la normalidad del sistema es una normalidad violenta, que depende de la desmoralización cotidiana de los minorizados [niñas, niños y mujeres]" (Segato, 2003, p. 121).

Para desarrollar esta idea, Graciela Hierro (1990) apunta que el orden moral que se instaura en el patriarcado es masculino. A este orden moral la autora lo denomina moral patriarcal. En este escenario la sujeción de las mujeres:

(...) es sancionada por la doble moral vigente, es decir la moralidad positiva impuesta por el grupo hegemónico y así se cierra el círculo que constriñe a las mujeres y las encuadra en los papeles tradicionales de reproductora, trabajadora doméstica, encargada del cuidado infantil y objeto erótico (Hierro, 1990, p. 10).

De acuerdo con la autora, la moral patriarcal se sustenta en tres elementos básicos: la biología de las mujeres, la hegemonía masculina y la educación formal (instituciones) e informal (familiar y social). Respecto a la primera, lo aprobado moralmente dependerá de las interpretaciones de lo que se considera natural para las mujeres y los hombres con base en sus funciones biológicas. Siendo así, el papel de la procreación (función reproductiva) es adjudicado de manera distinta para ambos sexos porque no cumplen la misma función: los hombres no conciben, las mujeres sí, de ahí que se "acepte moralmente que los hombres ejerciten su sexualidad para obtener placer” (Hierro, 1990, p. 47), mientras que las mujeres son condenadas moralmente a la procreación como la llave de acceso a su sexualidad.

De esta manera, se observa cómo el comportamiento moral permitido para hombres y para mujeres es desigual: por un lado, es natural que los hombres ejerzan su sexualidad y, por otro lado, se considera bueno y natural que las mujeres deban tener hijos para "satisfacer las necesidades de seguir su "instinto materno" y, al mismo tiempo, asegurar la necesidad social de perpetuación de la especie” (Hierro, 1990, p. 95). En tal sentido, se construye una moral que tradicionalmente considera la maternidad como el destino que todas las mujeres deben alcanzar, de ahí que la identidad femenina se constituya sobre la base de sus funciones como esposa y madre.

Lo anterior se refuerza mediante la educación formal e informal de las mujeres. Lugar desde donde se reproduce y perpetúa la moral patriarcal porque se les educa para la maternidad y la sumisión al esposo, se les confina en el ámbito de lo privado (doméstico) y se les responsabiliza del cuidado y bienestar de sus familias con el "objetivo primordial de conformarlas para que cumplan un papel secundario dentro del trabajo creativo y de las jerarquías de poder dentro de la sociedad" (Hierro, 1990, p. 51). Respecto a la hegemonía masculina, se tiene que esta es posible gracias a la "posesión y ejercicio de todas las fuerzas físicas, económicas e intelectuales por parte de todos los hombres" (Hierro, 1990, p. 10). Es decir, la autoridad moral deriva de los hombres, con base en la superioridad que les es conferida por el sistema patriarcal. 
En la construcción de estereotipos y roles la pasividad se establece como la manera de ser propia de las mujeres y a los hombres, por el contrario, se les educa en la agresividad para que se desarrollen en el ámbito de lo público. ${ }^{8}$ De esta manera, se producen valores asociados a lo femenino o como Hierro (1990) los denomina "valores femeninos" (p. 17), puesto que no se trata de valores humanos que son compartidos por los hombres, sino que más bien se configuran como mecanismos de control. Así los rasgos característicos de la mistificación femenina que se consideran positivos o buenos para las mujeres son la pasividad, la delicadeza, la debilidad, la pureza y la ignorancia.

En este orden de ideas, la moral tradicional conserva el orden patriarcal existente, mantiene los privilegios establecidos para los hombres y permite la reproducción de la violencia ejercida contra las mujeres, en especial aquella que se ejerce cuando ellas incumplen con los estereotipos de género asignados e internalizados como la manera de ser propia de las mujeres y, aún más, aquella que coacciona en lo cotidiano, como es la violencia moral. Lo anterior influye en la interpretación de las denuncias que las mujeres presentan ante instancias oficiales de la justicia, también influye en la aplicación de la ley, ya que produce concepciones estereotipadas sobre la mujer-víctima y su identificación como tal. El derecho, entonces, crea un tipo de género al definir tipos penales (como las lesiones) que no menoscaban o contravienen a la hegemonía masculina, ya que la violencia contra las mujeres es un problema complejo que no se limita al daño físico.

\subsection{La violencia sin huella}

En este apartado se desarrolla el análisis de los datos empíricos recabados en el Centro de Justicia para Mujeres en Querétaro (CEJUM), ${ }^{9}$ donde se ubica la Unidad IV de la Fiscalía General del Estado dedicada a la investigación de delitos sexuales, violencia familiar y en agravio del menor, junto a dicha "Unidad IV" también se encuentra un módulo del Instituto Queretano de la Mujer. Para dicho análisis se recurrió a la etnografía en espacios de justicia, espacio donde se documentó el proceso de denuncia y el de judicialización de la violencia moral. También se recuperan entrevistas a operadoras de justicia y mujeres víctimas de violencia, ${ }^{10}$ consideradas como sujetas sociales, históricas y políticas, con esta acción sus voces se extraen del anonimato o de la intrascendencia a la que son supeditadas sus experiencias de vida (etnografía feminista).

En términos formales, de acuerdo con el Protocolo para la Atención de Usuarias y Víctimas en los Centros de Justicia para las Mujeres en México (2012), dichos centros tienen como propósito ofrecer "servicios interinstitucionales y especializados para facilitar el acceso a la justicia y brindar atención integral con perspectiva de género a las mujeres que han sido víctimas de los delitos relacionados con la violencia de género" (Protocolo, 2012, p. 17). No obstante, a través del trabajo de campo realizado en el CEJUM de la ciudad de Querétaro, fue posible advertir cómo, de manera constante, se desestiman las denuncias por parte de la Fiscalía debido a que las mujeres no presentan signos de violencia física. En este apartado se exponen estas experiencias.

Respecto al derecho de acceso a la justicia, este va más allá de la posibilidad de acudir ante los órganos de justicia, pues el derecho implica el acceso propiamente dicho, es decir, llegar al sistema judicial (Protocolo, 2012). Asimismo, incluye el respeto hacia las garantías procesales de las víctimas, parte de estas garantías consiste en que "le reciban todos los datos o elementos de prueba con los que cuente" (Fromow, 2018, p. 51). Las víctimas tienen derecho a impugnar las actuaciones del ministerio público (ahora Fiscalía) cuando este, sin razón fundamentada en la ley, decida no ejercer la acción penal. De igual manera, se señala que la víctima tiene derecho a recibir, desde la comisión del delito, atención médica y psicológica de urgencia.

Aunado a lo anterior, el Protocolo establece que el servicio que se proporcione "debe ser otorgado de manera completamente imparcial y sin prejuicios respecto de las usuarias. Ello implica actuar y decidir sin inclinaciones, ni tomar posturas anticipadas o preferencias de cualquier tipo" (Protocolo, 2012, p. 38). Si bien se advierte que las personas operadoras deben evitar reproducir estereotipos de género, es necesario 
entender que estos se configuran como "construcciones sociales que forman parte del mundo de lo simbólico y constituyen una de las armas más eficaces contra la equiparación de las personas” (Casares, 2008, p. 52). Es decir, las personas que no se adaptan a los estereotipos de género son consideradas como personas anómalas "la desviación del estereotipo de género suele estar socialmente condenada con la intención de mantener el orden sexual-generizado imperante" (Casares, 2008, p. 53).

Durante el trabajo de campo, se colaboró con una dependencia pública que estaba realizando encuestas en el CEJUM-Querétaro a las usuarias (mujeres-víctimas), a estas se les preguntó cómo consideraban la prestación del servicio, si conocían sus derechos, si el procedimiento a seguir había sido claro, si consideraban haber sufrido algún tipo de discriminación y, por último, cuáles eran sus sugerencias para mejorar el servicio. Si bien estas preguntas se acotaban a cuestiones administrativas, las mujeres narraban su experiencia no solo en relación con la atención recibida al interior del CEJUM, sino también con relación a sus vivencias con la violencia. Con el propósito de contrarrestar el silenciamiento que estas mujeres han enfrentado al querer realizar las denuncias, negándoseles la posibilidad de contar sus historias, a continuación, se comparten fragmentos de tres experiencias para visibilizar los casos de violencia que son desestimados, pero también, para analizar el papel que juegan los estereotipos y la violencia moral en el desistimiento de la acción penal.

El día 11 de febrero, una mujer de aproximadamente 40 años acudió al CEJUM-Querétaro para levantar una denuncia en contra de su pareja. Al salir del centro accedió a contestar la encuesta, al preguntarle cómo consideraba la prestación del servicio la mujer señaló que el servicio era pésimo y comenzó a explicar que la fiscal no había querido levantar su denuncia, pues esta fiscal argumentó que no tenía golpes. Ella insistió expresándole: “`sabes lo que me va a pasar ahorita que salga?, mi agresor está aquí afuera” (Anónimo, comunicación personal, 11 de febrero de 2020). La fiscal le respondió que ella no podía hacer nada y que, si tenía miedo, podía llamar al 911. Al día siguiente, la misma mujer se presentó en el CEJUM, en esta ocasión venía acompañada por una licenciada del Instituto Queretano de la Mujer y cubría sus ojos con unos lentes oscuros, sin embargo, los golpes en su rostro eran evidentes, en esta ocasión, la fiscal sí procedió a levantar la denuncia.

Otro caso ocurrió el día 14 de febrero de 2020 durante la realización de las encuestas. Una mujer de aproximadamente 20 años, con un bebé en brazos y en compañía de otra mujer, accedió a responder la encuesta. Cuando se le preguntó si conocía sus derechos y el procedimiento a seguir ella señaló:

(...) no me quisieron levantar la demanda, me acaban de mandar a la agencia I y me dijeron que aquí no es, cuando les estoy diciendo que mi licenciada me dijo que aquí me tenían que atender, que viniera aquí a la IV (Anónimo, comunicación personal, 14 de febrero de 2020).

Cuando se le preguntó cuál era el motivo de su visita al CEJUM, la mujer comenzó a contar que su expareja la estaba amenazando de muerte a ella y a su hijo, ella señaló:

(...) me escribieron mensajes en el Facebook diciéndome que me van a matar y que a mi hijo me lo van a desaparecer. Yo le dije ahorita a la fiscal que es él, el papá de mi hijo, que se está escondiendo detrás de su nueva novia para amenazarme, pero la fiscal me dijo que no, que si es ella [para referirse a que era una mujer quien le enviaba los mensajes] debía de ir a la agencia I. Se me puso al tú por tú y me dijo: -te estoy diciendo que es en la uno, aquí no es. Le dije: -pero es que es él, sabe demasiados detalles, es él. Me dijo: -pues ya te dije que aquí no es, ve a la uno. Le enseñé el papel que me dieron allá en los juzgados, es una orden para que él no se acerque al niño, y me dijo: -sí, pero esa orden es por quince días, ya te dije que vayas allá. Es la segunda vez que vengo, la primera vez me dijo una fiscal que para proceder yo tenía que sacar ese papel allá en los juzgados y ya lo saqué ya traigo aquí la orden, pero no me quisieron atender, ni siquiera me dejó explicarle nada, yo temo por mi vida y por la de mi hijo, mi familia, mis papás, mis amigos están preocupados porque ya vieron que en el "face" [para referirse a la red social de Facebook] me dicen que me van a matar y que me van a quitar a mi hijo, a mi hijo no lo bajan de bastardo, me insultan (Anónimo, comunicación personal, 14 de febrero de 2020).

Mientras la mujer narraba su experiencia, dirigía su mirada para diversos lados de la calle y señalaba:

(...) es que yo tengo miedo y tengo más miedo por mi hijo, yo como quiera no importo, pero mi hijo sí. ¿Qué tiene que pasar para que me hagan caso?, que mañana amanezca muerta, que mañana a mi hijo se lo lleven y nunca lo vuelva a ver, que 
mañana seamos dos los desaparecidos y mi familia nunca vuelva a saber de nosotros, a ver, ahorita voy a la agencia I y de la agencia I me van a mandar otra vez para acá diciéndome que ahí no es, yo no puedo andar en la calle, para todos lados con mi hijo (Anónimo, comunicación personal, 14 de febrero de 2020).

Para analizar las situaciones anteriores, se retoma a Debora Daich (2004), quien plantea que al interior del campo jurídico se ha construido una determinada noción de la mujer-víctima:

(...) acorde al lugar que la mujer ha ocupado históricamente en el discurso y tratamiento judicial, la persona victimizada aparece débil, ignorante de sus derechos y necesitada de protección, a ello se le suma la imagen de la "mujer maltratada" que refiere a un estereotipo ampliamente compartido (p. 334).

En consecuencia, las mujeres víctimas de violencia son consideradas como sumisas, débiles e ignorantes (moral patriarcal) frente a su agresor y frente a la justicia. Este estereotipo de mujer maltratada permite a las personas operadoras de justicia clasificar los casos de acuerdo con la apariencia física de las mujeres, es decir, para parecer una verdadera víctima, las mujeres deben verse frágiles, desarregladas o dejadas. Lo que se intenta señalar es el papel que juegan estos estereotipos para que las personas operadoras de justicia tomen o desestimen de forma preliminar las denuncias. Los casos descritos arriba fueron descartados a primera vista por las fiscales, es decir, realizaron una valoración a partir de la imagen de la mujer maltratada sin conocer mucho más sobre los hechos de violencia.

Abonando a estos aspectos, en una de las entrevistas realizadas a una psicóloga perita que trabajó en el área de atención psicológica por más de ocho años en el CEJUM- Querétaro, ella señala que al interior del centro de justicia se espera un tipo especial de víctima:

(...) creo que uno de los grandes, a veces, como errores que se cometen en los ámbitos judiciales o institucionales, es que justamente se espera ver a un tipo de persona, que se vea de cierta forma y la experiencia de la violencia, aunque hay un ciclo o que hay un cuadro, hay conductas que son repetitivas, me parece que la experiencia de quien vive la violencia es distinta, o sea, se sufre o se padece de distintas maneras y se asume de diferentes maneras [...] me hace pensar en la experiencia dentro de la agencia [señala la agencia para referirse a la Fiscalía dentro del CEJUM] había, por ejemplo, mujeres que se presentaban con un descuido total de su persona y otras que por el contrario no, que había como una cuestión impecable en su aspecto (Psicóloga perita, comunicación personal, 30 de marzo de 2020).

Para Encarna Bodelón (2014), los estereotipos presentes en la judicialización de la violencia contra las mujeres no solamente se relacionan con la no adecuación de las mujeres a las imágenes de la mujer maltratada, sino también con el estereotipo de la violencia que deja buella. "Las violencias reiteradas y diversas en sus formas son transformadas por el sistema penal en fenómenos en su mayoría que aparecen como violencias puntuales y que mayoritariamente adoptan la forma de violencias físicas” (p. 142). Siendo así, violencias no visibles o sutiles como la violencia psicológica o moral, prácticamente desaparecen del ámbito penal y, a su vez, la violencia física es desarticulada de un entramado mucho más complejo, lo cual se ha demostrado a través de las experiencias expuestas.

Otro caso documentado por medio de una entrevista en profundidad se trata de una mujer-víctima que tampoco consiguió interponer su denuncia. Karina ${ }^{11}$ vivió violencia de género durante más de tres años por parte de su expareja. Cuando tenía 19 años comenzó a salir con un hombre que vivía cerca de su casa. Al inicio de la relación, ella señala: "como que él era pues buena onda, un chavo que yo decía ay pues es buena gente, me trata bien” (Karina, comunicación personal, 07 de octubre de 2020). Avanzada la relación, Karina notó que él cambió, comenzó a aislarla de su familia, sus amigos y le prohibió continuar con sus estudios, "pero entonces, en ese tiempo me aisló completamente, yo ya no veía a mis amigos, o sea como que se hizo muy, muy violento" (Karina, comunicación personal, 7 de octubre de 2020).

Karina mencionó que no sabía qué hacer a pesar de reconocer que su pareja tenía actitudes que no le gustaban:

(...) pero cuando yo ya reconocí que, pues era una violencia así ya muy marcada, ya no podía salir, me sentí contra la pared, yo ya no supe que hacer, no, porque este chavo me golpeaba, abusaba de mí sexualmente, él era drogadicto, o sea era una persona 
muy, muy agresiva, entonces yo sí le tenía miedo, o sea yo le tenía miedo de que, pues si me fuera hacer algo a mi familia, a mi hermano, a mis papás (Karina, comunicación personal, 7 de octubre de 2020).

Como resultado de las múltiples ocasiones en que su expareja la obligó a tener relaciones sexuales, Karina quedó embarazada dos veces, en ambas, decidió interrumpir el embarazo:

(...) al principio me decía que él no se iba a hacer cargo, que si buscáramos la opción de interrumpirlo, pero ya cuando vio que era en serio, que yo ya estaba buscando las opciones para interrumpir ese embarazo, fue de que, no por qué, si es mi hijo, cómo le vas a hacer eso, o sea como que se puso en ese plan, pero pues de todas maneras yo lo hice, pero de todas maneras él utilizaba la culpa para que yo volviera a estar con él, y volvió a pasar lo mismo y volví a quedar embarazada, o sea yo me sentía tan estúpida porque yo decía, cómo me volvió a pasar [...] pero yo no podía cuidarme, o sea yo sí le decía, sabes que, vamos a utilizar preservativo, póntelo, él se lo quitaba, o sea cosas así y aparte me obligaba a tener relaciones, o sea imagínate yo cómo me sentía, o sea fueron procesos emocionales bien fuertes (Karina, comunicación personal, 7 de octubre de 2020).

No obstante, en la segunda ocasión, casi pierde la vida como consecuencia de un aborto mal practicado, ella señala que su expareja lo único que hacía era llamarla pendeja:

(...) este chico y su mamá me llevaron al hospital, pero pues ya sabes no, este tipo súper agresivo en el taxi me decía: estás bien pendeja. Y pues yo desangrándome, te juro que estaba sangrando de una manera que yo sabía que no era normal y ya hasta me sentía mal, ya hasta como que la presión se me estaba bajando, así fue, yo sentía que me iba a morir, yo sentía que ya no llegaba al hospital (Karina, comunicación personal, 7 de octubre de 2020).

Karina señala que la familia de su pareja sabía de esa violencia y no hacía nada:

(...) lo peor de todo es que su familia era cómplice, porque o sea, él vivía con sus papás todavía, entonces, cuando yo iba a su casa, pues ahí estábamos y sus papás llegaban a ver, o sea te lo juro era una cosa horrible de que veían. Una vez él me dio un cabezazo aquí en esta parte [Karina lleva su mano a su cien] y se me hinchó horrible, y ellos no se metían ni para bien ni para mal, nada más le decían ya, o ya cuando veían que él me estaba golpeando pues ya, en serio, que ya veían que ya estaba muy lastimada me decían: -ya perdónalo para que te deje (Karina, comunicación personal, 7 de octubre de 2020).

En este punto es posible observar la normalización de la violencia por parte de la familia del agresor, es decir, la aceptación social de estos comportamientos, su arraigo y la incapacidad de percibir sus consecuencias, pero también, la sumisión y pasividad que las mujeres deben tener frente a los varones como mandato del orden moral establecido en la moral patriarcal (Hierro, 1990). Una de las consecuencias de esto, se relaciona con lo que Karina apuntó de manera reiterada en las entrevistas respecto a no poder salir de esa relación y sobre sentirse atrapada y desmoralizada:

(...) pues siento que fue a raíz del miedo, o sea como que, si de por si yo tenía una autoestima bien mal, toparte con una persona así de agresiva, imagínate cómo te destruye, o sea te desmoraliza, o sea como que te envuelven y ya, o sea no te sientes capaz de salir de eso, es como decir ya, o sea no tengo de otra, así me sentía yo. Imagínate es como constantemente estar en un lugar del que tú sabes que tienes que salir y no puedes, no puedes, o sea yo ahorita ya me acuerdo de eso y todavía me duele mucho y la verdad siento muy feo recordarlo [hace pausa] y me da tristeza de no haber tenido o no haber sido capaz de haber dicho no, de haber roto el miedo y decir no me va a hacer nada, ya no lo voy a permitir, porque permití muchas cosas que acabaron con mi integridad que casi acaban con mi vida (Karina, comunicación personal, 7 de octubre de 2020).

Siguiendo los planteamientos de Segato (2003), respecto a la separación analítica de la violencia física de la violencia moral, Karina además de recibir golpes y ser abusada sexualmente por parte de su expareja de manera reiterada, también era víctima de violencia moral. Existía agresión emocional, intimidación, miedo, desvalorización de sus capacidades intelectuales, pérdida de su autonomía y desmoralización. Todo esto, de acuerdo con Segato (2003), es la forma más eficiente y habitual de "reducir la autoestima, minar la autoconfianza y desestabilizar la autonomía de las mujeres. La violencia moral, por su invisibilidad y capilaridad, es la forma corriente y eficaz de subordinación y opresión femenina, socialmente aceptada y validada" (p. 115).

Respecto a este punto, la psicóloga perita entrevistada señala que una condición psicológica que produce la violencia en las mujeres que la padecen, es la idea de no poder salir de esa situación: "como una concepción 
de estar ahí atrapadas y no poder romper ese círculo" (Psicóloga perita, comunicación personal, 18 de marzo de 2020). Esta situación es interpretada por las instituciones de justicia de una manera diferente porque las mujeres son culpabilizadas de la violencia que padecen. De esta forma, se crea género al reproducirse el estereotipo de la mujer-víctima como sumisa, desvalida e ignorante de sus derechos, manteniéndose así, las posiciones asimétricas entre hombres y mujeres. En este sentido, la psicóloga perita señala:

(...) me parece que uno de los grandes conflictos es que se sigue percibiendo a las mujeres como parte del problema, o sea, como responsables de ese círculo o ese ciclo de violencia en el que se encuentran inmersas, muchas de las veces la primera pregunta que se hace o se les hace por parte de las autoridades es ¿qué hace usted ahí? (Psicóloga perita, comunicación personal, 18 de marzo de 2020).

Es así como se evita situar el problema de la violencia dentro del orden patriarcal para ubicarlo en la mujervíctima. Todo esto es reforzado desde los valores, discursos y prácticas familiares, sociales y también jurídicas, relacionadas con el mandato moralizador cuyos actos, vistos como mecanismos de control social, acentúan y preservan los estereotipos de género, es decir, las relaciones de desigualdad entre mujeres y hombres. Desde esta misma idea, se puede seguir observando la última parte de la experiencia de Karina.

El suceso que permitió a Karina tomar la decisión de romper el silencio y acudir a la unidad IV de la Fiscalía en el CEJUM-Querétaro para realizar la denuncia fue cuando su papá vio cómo su expareja la estaba golpeando en la calle:

(...) mi papá ve cuando él me estaba agrediendo, entonces, lo que hace mi papá es bajarse del carro y empezar a pelearse con él, pero este tipo también le pegó, o sea le fisuró una costilla a mi papá, o sea fue una escena tan horrible (Karina, comunicación personal, 7 de octubre de 2020).

Sin embargo, la familia de Karina la culpó después de este hecho y, su madre le reprochó la agresión de la que había sido víctima su padre, la cual se había dado por el hecho de que ella se encontrara en una relación violenta:

(...) mi mamá me dijo: eres una pendeja, por tu culpa tu papá se tuvo que pelear. O sea, como que toda la culpa recayó en mí, la culpa de haber permitido una relación violenta y la culpa de que mi papá se haya peleado a golpes con ese tipo (Karina, comunicación personal, 7 de octubre de 2020).

Cuando Karina fue a la Fiscalía en el CEJUM-Querétaro y comenzó a explicarle a la fiscal su situación de violencia, igual que en los ejemplos anteriores, le dijeron que su denuncia no procedía:

(...) le dije que él me acosaba, que era una persona que no me la podía quitar de encima, aunque yo le decía ya no quiero nada de ti, lo bloqueaba y de la forma como podía me mandaba mensajes de otras cuentas en Facebook, o él hacia otras cuentas. Como yo por las mañanas me quedaba sola al cuidado de mi sobrina, él se metía por la fuerza a mi casa a golpearme [...]. El pretexto fue que él no me podía haber estado acosando que porque los mensajes que me mandaba no tenían contenido sexual y que yo no tenía golpes visibles, imagínate yo la impotencia que sentí, es como si mi vida no valiera, como si todo lo que él me hizo a nadie le importara, porque aparte la forma en la que me trataron fue así, jamás voy a olvidar la cara de la fiscal, yo le estaba diciendo lo que estaba pasando y ella volteaba los ojos [Karina imita los gestos que la fiscal hacía], así como de ya te apuras. O sea, imagínate, fue lo que tuve que aguantar por casi tres años y que se quede impune, porque aparte, me lo tengo que encontrar en la calle y nadie le hizo absolutamente nada (Karina, comunicación personal, 7 de octubre de 2020).

Lo que se intenta demostrar es que la violencia moral ejercida en contra de Karina fue normalizada, lo cual dificultó no solo percibir y nombrar dichas acciones, sino también, considerarlas como violencia para denunciarlas. Como parte de la violencia moral, Karina fue culpabilizada por las consecuencias que sí fueron visibles, centrando en ella la causa y no en el orden patriarcal. Todo esto fue reproducido por la familia del agresor, por su propia familia y por la autoridad judicial, como un mecanismo que refuerza las relaciones asimétricas. Tal y como lo plantea Segato (2003), en la violencia moral se ejerce una crueldad de orden sutil y moral en un mundo patriarcal que organiza relaciones tensas y crueles. "Y cuando la crueldad es física, no puede prescindir del correlato moral: sin desmoralización no hay subordinación posible. Y si fuera posible 
una crueldad puramente física, sus consecuencias serían inevitablemente también morales” (Segato, 2003, p. 122).

Con relación a los estereotipos aquí analizados en los tres casos expuestos, es posible determinar que en estos la autoridad judicial juega un papel central, ya que las personas operadoras de justicia descartan una denuncia no por lo acontecido o por tener en cuenta los hechos de violencia, sino por lo que observan a primera vista. Así la mujer-víctima se preconcibe como aquella que solo presenta signos de violencia física y como aquella que se ajusta al estereotipo de violencia que subsiste al interior de las instancias de justicia, en donde la violencia deja huellas visibles, o bien, donde el sufrimiento o daño que produce la violencia física es evidente. Estos estereotipos se materializan en la judicialización de los conflictos de violencia contra las mujeres en materia penal en Querétaro, ya que la mayoría de los casos que ingresan son clasificados como delitos de lesiones, ${ }^{12}$ a pesar de que también se encuentran tipificadas la violencia familiar y la violencia de género. ${ }^{13}$

\section{CONCLUSIONES}

De acuerdo con Bodelón (2014), la violencia ejercida contra las mujeres no se trata únicamente de lesiones, ya sean físicas o psicológicas, en el sentido de como son entendidas las lesiones en las lógicas del derecho penal, es decir, no se trata solamente de un daño producido en la salud de otra persona. ${ }^{14}$ En este escenario de violencia, se debe comprender que se trata de violencia de género ejercida contra las mujeres, la cual opera como manifestación de la discriminación social en términos de la opresión y la subordinación hacia las mujeres que se instaura dentro de un sistema patriarcal y esta violencia tiene múltiples expresiones. Lo que sucede es que la clasificación basada en el estereotipo de la violencia física queda enmarcada solo en el contexto de la estructura patriarcal, estructura que le da sustento y que al mismo tiempo invisibiliza formas de violencia que no son físicas.

Lo anterior se configura como un obstáculo para la judicialización de la violencia moral al interior de las instituciones de justicia en Querétaro, instancias que, en términos formales, deben proteger a las mujeres y garantizar su acceso a la justicia. Las experiencias presentadas demuestran que no toda la violencia ejercida contra las mujeres es perceptible o deja huellas visibles. La violencia moral se manifiesta de formas variadas y puede ser muy sutil. Su sustento en valores morales (moral patriarcal) desde el interior de la familia provoca que sea considerada como normal o como la manera de ser propia de las mujeres, lo cual también incide en su invisibilización.

Es así como la imagen de la mujer víctima ideal, construida como un estereotipo asociado a lo femenino, cobra sentido tanto para las personas operadoras de justicia como para la sociedad. La pasividad, la sumisión, la ignorancia y la huella física de la violencia serán requisitos necesarios para la acción penal. Esto se refleja en los casos que logran judicializarse, los cuales son clasificados, en su mayoría, como lesiones. Todo esto fue posible advertirlo desde una perspectiva crítica feminista, que concibe al derecho no como una unidad coherente, autónoma y neutral en términos de género, sino como un productor y reproductor de género. En este sentido, el derecho y, sobre todo, el derecho penal, no opera de igual manera frente a las personas, puesto que en este influyen, necesariamente, las condiciones de género, clase, etnia y orientación sexual (Núñez, 2018).

Por su parte, Segato (2003) apunta que el derecho es atravesado por la tradición patriarcal y termina por reproducir las relaciones de desigualdad entre los géneros esto configura lo que la autora denomina la ambivalencia de la ley: Por un lado, se requiere una ley moderna e igualitaria, y por otro, esta "permanece con los pies de barro profundamente hincados en el sistema de estatus que es el género" (Segato, 2003, p. 125). De esta manera, cuando las historias de violencia de las mujeres penetran en la esfera judicial, las denuncias de las mujeres son desestimadas, la violencia ejercida en su contra es descontextualizada de la estructura patriarcal 
o dichas denuncias son transformadas en forma de problemas legales. Lo anterior produce que esta imagen o este estereotipo de lo que debe ser la mujer maltratada no sea cuestionado por las y los operadores de justicia, es decir, no se da un cuestionamiento que permita observar y tratar la violencia contra la mujer como una construcción histórica, social y cultural basada en estereotipos del deber ser de las mujeres.

A pesar de la vigencia de distintos ordenamientos de protección de los derechos humanos de las mujeres, entre los que se incluye, vivir una vida libre de violencia, el problema de la violencia de género ejercida contra las mujeres no puede erradicarse por decreto de una ley, sino que se requiere minar o desgastar la estructura jerárquica que coloca a los géneros en posiciones diferenciadas y que produce la subordinación y opresión de las personas asociadas con el género femenino. Asimismo, se requiere comenzar a dar luz a otras formas de violencia no visibles ejercidas contra las mujeres y utilizar el derecho y el sistema penal con cautela minimalismo penal-, ya que desde y con él se producen y reproducen relaciones de género.

\section{REFERENCIAS BIBLIOGRÁFICAS}

Álvarez, N. (2016). La moral, los roles, los estereotipos femeninos y la violencia simbólica. Revista humanidades, 6(01), 1-32. http://dx.doi.org/10.15517/h.v6i1.24964

Birgin, H. (2000). Las trampas del poder punitivo: el género del derecho penal. Biblos.

Bodelón, E. (2014). Violencia institucional y violencia de género. Revista de la Universidad de Granada, 48, 132-154. https://revistaseug.ugr.es/index.php/acfs/article/view/2783/2900

Casas, L. (2010). Introducción a los problemas de género en la justicia penal en América Latina. Centro de Estudios de Justicia de las Américas (CEJA).

Casares, A. (2008). Antropología del género. Culturas, mitos y estereotipos sexuales. Catedra.

Castañeda, M. (2012). Etnografía feminista. En M. Aguiluz et al. (Eds.), Investigación feminista, epistemología, metodología y representaciones sociales (pp. 217-238). Centro de Investigaciones Interdisciplinarias en Ciencias y Humanidades; Centro Regional de Investigaciones Multidisciplinarias; Facultad de Psicología UNAM.

Daich, D. (2004). Los procedimientos judiciales en los casos de violencia familiar. En A. Bonilla et al. (Eds.), Burocracias y Violencia. Estudios de Antropología Jurídica (pp. 327-380). Facultad de Filosofía y Letras de la Universidad de Buenos Aires.

Facio, A. (1992). Cuando el género suena cambios trae (una metodología para el análisis de género del fenómeno legal). ILanud.

Fernández, A. (1998). Estudios sobre las mujeres, el género y el feminismo. Revista Nueva Antropología, 16(54), 79-95. https://revistas-colaboracion.juridicas.unam.mx/index.php/nueva antropologia/article/view/15761/14082

Fromow, M. (2018). Los retos y desafíos de las víctimas en el sistema penal acusatorio. En Instituto de Estudios Constitucionales del Estado de Querétaro (Ed.), Memoria del Congreso Nacional de Justicia Penal 2018 (pp. 49-57). Instituto de Estudios Constitucionales del Estado de Querétaro.

Hierro, G. (1990). Ética y feminismo. Universidad Nacional Autónoma de México.

Kant, R. y Lupetti, B. (2014). Como a Antropología pode contribuir para a pesquisa jurídica? Um desafio metodológico. Revista electrónica: Anuario Antropológico, 39(2), 9-37. http://aa.revues.org/618

Lachenal, C. (2016). Justicia sin perspectiva. Violencia contra las mujeres en el nuevo sistema de justicia penal en Oaxaca. Fundar, Centro de Análisis e Investigación, A.C.

Larrandart, L. (2000). Control social, derecho penal y género. En Centro de Apoyo al Desarrollo Local (CEADEL) (Ed.), Las trampas del poder punitivo: el género del derecho penal (pp. 85-109). Biblos.

Ley General de Acceso a las Mujeres a una Vida Libre de Violencia. (2007). Congreso General de los Estados Unidos Mexicanos, Diario Oficial de la Federación (01 de febrero de 2007)

Núñez, L. (2015). La violencia de género en la ley penal. En M. Rodríguez-Shadow, y B. Barba (Eds.), Trabajo y Violencia. Perspectivas de Género (pp. 241-257). Centro de Estudios de Antropología de la Mujer. 
Núñez, L. (2018). El género en la ley penal: crítica feminista de la ilusión punitiva. Centro de Investigaciones y Estudios de Género de la Universidad Nacional Autónoma de México (UNAM).

Otano, G. (2000). La mujer y el derecho penal: una mirada de género. En Centro de Apoyo al Desarrollo Local (CEADEL) (Ed.), Las trampas del poder punitivo: el género del derecho penal (pp. 111-135) Biblos.

Pardo, J., Díaz, A. y Baraíbar, C. (2019). Nuevo sistema de justicia penal en su interacción con los medios de control constitucional. Análisis a partir de la jurisprudencia de la SCJN. Tirant lo Blanch.

Pitch, T. (2018). Introducción. En Centro de Investigaciones y Estudios de Género (Ed.), El género en la ley penal: crítica feminista de la ilusión punitiva (pp.7-9). Centro de Investigaciones y Estudios de Género de la Universidad Nacional Autónoma de México (UNAM).

Ponce, M. (2019). La epistemología del procedimiento penal acusatorio y oral. Instituto de Estudios Constitucionales del Estado de Querétaro.

Protocolo para la Atención de Usuarias y Víctimas en los Centros de Justicia para las Mujeres en México (2012). Secretariado Ejecutivo del Sistema Nacional de Seguridad Pública, Centro Nacional de Prevención del Delito y Participación Ciudadana, Instituto Nacional de Ciencias Penales.

Segato, R. (2003). Las estructuras elementales de la violencia. Ensayos sobre género, entre la antropología, el psicoanálisis $y$ los derechos humanos. Universidad Nacional de Quilmes.

Spaventa, V. (2002). Género y control social. Biblioteca jurídica virtual del instituto de investigaciones jurídicas de la UNAM. https://revistas-colaboracion.juridicas.unam.mx/index.php/lecciones-ensayos/article/view/34711/ 31684.

\section{Notas}

1 Este artículo se ubica dentro del campo de estudios realizados por Graciela Otano (2000), Lucila Larrandart (2000), Veronica Spaventa (2002), Deborah Daich (2004), Lidia Casas (2010), Cecile Lachenal (2016) y Lucia Núñez (2015, 2017 y 2018) quienes han problematizado, desde perspectivas multidisciplinarias e interdisciplinarias de los estudios de género, el tratamiento de la violencia contra las mujeres en el ámbito de la justicia penal en el contexto latinoamericano, relacionando elementos normativos, socioculturales e históricos implicados en estos procesos de resolución de controversias.

2 La Convención sobre la eliminación de todas las formas de discriminación contra la mujer (CEDAW) en 1979, la Convención Interamericana para la Prevención, Sanción y Erradicación de la Violencia contra la Mujer (Convención Belém do Pará) en 1994, la cuarta Conferencia Mundial sobre la Mujer celebrada en Beijing en 1995.

3 Plantearon la violencia contra las mujeres como un problema de salud pública.

4 El Estado mexicano desde 1981 ha venido firmando estas disposiciones internacionales.

5 Ver Pardo, Díaz y Baraíbar (2019); Ponce (2019).

6 De acuerdo con Tamar Pitch, el feminismo jurídico no constituye una teoría, "sino una literatura variada y plural, en diálogo constante con las luchas de las mujeres” (Pitch, como se citó en Núñez, 2018, p. 8). En ese sentido, incluye diversos enfoques y múltiples miradas.

7 Desde los años 70 del siglo XX, varias autoras feministas como Millet (1975); Firestone (1976); Mitchel (1977), Hartmann (1980); Eisenstein (1980), desde el feminismo socialista y radical, se apropiaron del vocablo patriarcado y se centraron en este: "dándole el significado de poder masculino sobre las mujeres, quedando subordinadas al mismo” (Fernández, 1998, p. 80). Estos son algunos de los antecedentes de la teoría de la opresión entre los géneros.

8 De acuerdo con Larrandart (2000), durante el siglo XIX la tarea de educar y reeducar a las mujeres en la docilidad y dependencia le fue confiada a las monjas, ellas asistían, vigilaban y educaban a las mujeres, "el objetivo de la reeducación era el "arrepentimiento", la resignación y la adecuación del comportamiento de las mujeres a los requerimientos de las monjas. Generalmente se imponían cuando el comportamiento no condecía con la "docilidad" femenina" (p. 97).

9 También se encuentra el Sistema Estatal para el Desarrollo Integral de la Familia a través de la Procuraduría de la Defensa del Menor y la Familia

10 El trabajo de campo etnográfico y las entrevistas se realizaron en el período de febrero-abril y septiembre-octubre de 2020.

11 Los nombres de las mujeres han sido cambiados con la intención de proteger su identidad y la confidencialidad de la información.

12 De acuerdo con las cifras del Secretariado Ejecutivo del Sistema Nacional de Seguridad Pública (SESNSP-2020), la mayoría de los casos ingresados son por lesiones dolosas, con un total de 2741 casos en Querétaro. 
Revista Humanidades, 2022, vol. 12, NÚM. 1, E48592, ISSN: 2215-3934

13 Ambas se encuentran reguladas, respectivamente, en el Capítulo VI: Violencia de género y Capítulo VIII: violencia familiar del Código Penal del Estado de Querétaro.

14 Art. 127 Código Penal del Estado de Querétaro. 